\title{
Activated carbon fiber composites for gas phase ammonia adsorption
}

Weihua Zheng, ${ }^{\mathrm{a}, \mathrm{b}}$ Jingtian Hu, ${ }^{\mathrm{c}}$ Sammuel Rappeport, ${ }^{\mathrm{a}}$ Zhen Zheng, ${ }^{\mathrm{e}}$ Zixing Wang, ${ }^{\mathrm{d}}$ Zheshen Han, ${ }^{\mathrm{a}}$ James Langer, ${ }^{\text {,** James Economy }}{ }^{\mathrm{a}, \mathrm{b}, *}$

a. Department of Materials Science and Engineering, University of Illinois at Urbana-Champaign, 1304 W Green St, Urbana, IL, 61801, USA. Email: jeconomy @illinois.edu.

b. Serionix, Inc., 60 Hazelwood Dr. Champaign, IL, 61820, USA. Email: jlanger@ serionix.com.

c. Department of Materials Science and Engineering, Northwestern University, Evanston, IL 60208

d. Department of Chemistry, Rice University, Houston, TX, 77005, USA.

e. School of chemical and chemical engineering, Shanghai Jiaotong University, Shanghai, China

\begin{abstract}
Low-cost activated carbon fiber composites (ACFCs) were explored as the basis for a system to remove $\mathrm{NH}_{3}$ from the gas phase. ACFCs were synthesized by chemically activating a phenolic precursor on a glass fiber substrate using $\mathrm{ZnCl}_{2}$ as catalyst. Additionally, ACFCs were oxidized with concentrated nitric acid at both room temperature and $83{ }^{\circ} \mathrm{C}$ to increase the density of surface oxygen groups. Commercially available phenolic-based physically activated carbon fibers were also oxidized under the same condition as a benchmark. Both physical properties and surface chemical properties of these materials were characterized using SEM, BET, elemental analysis, FTIR, XPS, and Boehm titration. Dynamic flowthrough $\mathrm{NH}_{3}$ adsorption was measured at $500 \mathrm{ppm}$, at both $0 \%$ and $50 \%$ relative humidity. Results suggest ACFCs exhibit high surface area, rich oxygen functional groups, with post-treatment further improving surface oxygen content. ACFCs displayed fast sorption kinetics and high $\mathrm{NH}_{3}$ adsorption capacity up to $50 \mathrm{mg} / \mathrm{g}$. Acidic oxygen groups at the surface are correlated with ammonia adsorption. A new anhydride-based reaction mechanism was identified and is proposed, collectively with carboxylic acid functional groups, as being primarily responsible for retaining $\mathrm{NH}_{3}$.
\end{abstract}

\section{Page 1}




\section{Introduction}

Ammonia $\left(\mathrm{NH}_{3}\right)$ is a notoriously hazardous chemical that is harmful to both industrial processes and human beings. For example, in the 193 nm-lithography semiconductor manufacturing process, trace $\mathrm{NH}_{3}$ levels as low as $1 \mathrm{ppb}$ are capable of damage to optics in the range of $\$ 5$ million for equipment and $\$ 10,000$ per hour for cleaning[1]. Fuel cells using acidic electrolytes suffer performance decay when fed gases containing more than $1 \mathrm{ppm}$ $\mathrm{NH}_{3}$ [2]. In the international space station (ISS), $\mathrm{NH}_{3}$ could be emitted from human or animal urine or refrigeration system leaks, posing a health risk to astronauts, and is thus regulated to below 7 ppm[3]. Beyond these hazards, $\mathrm{NH}_{3}$ is also regarded as one of the most dangerous Toxic Industrial Chemicals (TICs) — a new concerns for military chemical defense [4]. Due to its wide availability, ease of acquisition in large quantities and high toxicity, $\mathrm{NH}_{3}$ could be used by terrorist to cause catastrophic casualties and injuries to civilians and military personnel. In all scenarios mentioned above, there is significant interest and need in developing an air filtration unit that can adsorb $\mathrm{NH}_{3}$ effectively, encompassing both ease of containment and tailored pressure drop compatible with existing air handling systems[4-7].

In the literature, several types of adsorbents have been previously investigated for ammonia adsorption including activated carbons, zeolites, alumina, silica, graphene oxides (GO)[8] and metal organic frameworks (MOFs)[9], with activated carbons emerging as the most effective solution due to their high surface area and low cost[10]. Since $\mathrm{NH}_{3}$ is a small molecule (diameter $3 \AA$ ) with very high vapor pressure $\left(10\right.$ atm at $25{ }^{\circ} \mathrm{C}$ ), physical adsorption by activated carbon is thermodynamically unfavorable[8]. Although only a limited amount of surface chemical functional groups are present on virgin activated carbon, chemisorption has been as the main factor-as opposed to physical adsorption-dictating $\mathrm{NH}_{3}$ 
uptake[11]. Unmodified granular activated carbons (GAC) and powdered activated carbons (PAC) have reported adsorption capacities ranging from 0.25 to $5.7 \mathrm{mg} / \mathrm{g}$ at 5,000 to 10,000 ppm of $\mathrm{NH}_{3}$ [11-13].To improve capacity, one approach is to tailor surface chemistry by maximizing acidic functional groups-a factor often quantified by oxygen content as characterized by elemental analysis or XPS[14]. Methods to increase O content include AC surface oxidation by sulfuric acid[13, 15], nitric acid[12, 14, 15], air[15], hydrogen peroxide and sodium dichloroisocyanurate[16]. Another common approach to modify AC is through impregnation of metal chloride salts or oxides, including $\mathrm{W}, \mathrm{V}, \mathrm{Mo}, \mathrm{Zn}, \mathrm{Cr}, \mathrm{Cu}$, etc[17-22]. Through these modifications, acidic surface functional groups have been dramatically increased along with an accompanying adsorption capacity ranging from $10-80 \mathrm{mg} / \mathrm{g}[11-13$, $16-21,23,24]$.

Besides adsorption capability, ease of containment and pressure drop are also critical factors for HVAC (heating, ventilation, and air conditioning) system design[25]. GAC has very slow kinetics due to the large geometry of granules; PAC has fast mass transfer, while extremely high pressure drop makes it impractical for air handling system. Fiber-form adsorbents, on the other hand, possess a unique combination of rapid kinetics, low pressure drop and simplified containment for HVAC applications [26, 27]. As a fabric forms of activated carbon, activated carbon fibers (ACFs) has been synthesized and studied for water and air purification ever since 1960s. The synthesis, development, and environmental applications of ACFs have been reviewed comprehensively by Suzuki[26], Economy[27], Le Cloirec[28], Cukierman[29], et al. For $\mathrm{NH}_{3}$ adsorption, Kynol based ACFs have been studied, and showed extremely poor affinity towards $\mathrm{NH}_{3}$. After oxidation treatment by nitric acid and sulfuric acid, ACFs showed tremendous increase in both adsorption capacities and 
breakthrough times[14]. Although the superior performance compared with GAC and PAC and extensive research activities [27], ACFs are only used in niche markets commercially due to its exceedingly high cost $(\sim \$ 500 / \mathrm{kg})$. If low cost ACFs were developed, it may raise great interests.

Objectives of the present study are to explore a low-cost activated carbon fibers system for $\mathrm{NH}_{3}$ adsorption, and investigate the correlations between surface chemistry and adsorbent-adsorbate interactions. In the present study, chemically activated carbon (CAFs) based on glass fiber substrates were synthesized and modified with surface oxidation. The low cost is achieved through use of both glass fiber substrate and activation catalysts, which greatly reduce the cost for both materials and processing temperature at approximately $400{ }^{\circ} \mathrm{C}$. More importantly, a primary advantage of these CAFs over ACFs is a rich distribution of surface functional groups originating from the precursor retained due to the low processing temperature[30]. This in turn proves effective for polar pollutants like $\mathrm{NH}_{3}$. In this work, first, the synthesis of a variety of ACFs and surface modifications is described; this is followed by characterization of surface chemistry and physical properties; afterwards, $\mathrm{NH}_{3}$ adsorption is evaluated in flowthrough configurations; at last, the mechanisms of ammonia adsorbate-adsorbent interactions are characterized and discussed.

\section{Materials and methods}

\subsection{Materials}

Novolac resin (Schenectady International Inc., HRJ-2190) was employed as a polymeric phenolic precursor, $\mathrm{ZnCl}_{2}$ (Sigma-Aldrich, Cat. 208086, 99\%) served as activation agent. Solvents include Ethanol (Decon, 200 proof) and DI Water. A non-woven glass fiber mat (Craneglas 230, Neenha Technical materials) with fiber diameter of $6.5 \mu \mathrm{m}$ was used due to 
ease of use and low cost. Commercial ACFs (Nippon Kynol ${ }^{\circledR}$, ACC-5092-20) were used asreceived.

\subsection{Synthesis}

Phenolic based chemically activated carbon fibers (CAFs) were synthesized based on previous work with modifications[31]. $30 \mathrm{~g}$ Novolac was dissolved in $200 \mathrm{ml}$ of ethanol at room temperature, followed by adding $30 \mathrm{~g}$ of $\mathrm{ZnCl}_{2}$. Craneglas mat was then dip-coated into the solution and dry at room temperature. Afterwards, the fiber mat was placed into a convection oven wherein the temperature was slowly raised from 110 to $170{ }^{\circ} \mathrm{C}$ over $8 \mathrm{hr}$. Next, the sample was transferred to an enclosed Lindberg furnace under $\mathrm{N}_{2}$ flow and heated to $400{ }^{\circ} \mathrm{C}$ at a rate of $30^{\circ} \mathrm{C} \mathrm{min}^{-1}$ and held for $30 \mathrm{~min}$ to activate. Afterwards, the sample was allowed to cool down under flowing $\mathrm{N}_{2}$. The sample was washed with $0.5 \mathrm{~N} \mathrm{HCl}$ and rinsed with DIW. The composite was then placed in a vacuum oven and dried at $150{ }^{\circ} \mathrm{C}$ overnight.

To further improve surface acidity and thus ammonia uptake, Phenolic based ACFCs were also post-treated with concentrated $\mathrm{HNO}_{3} .1 \mathrm{~g}$ of Phenolic CAF (labeled as Phenolic) was placed in concentrated $\mathrm{HNO}_{3}$ at either room temperature (labeled as Ph-Nitric-RT) or $83{ }^{\circ} \mathrm{C}$ (Ph-Nitric-80). After the reaction, samples were washed with DIW several times to remove residual acid. Afterwards, samples were dried in a hood and then vacuum dried at $100{ }^{\circ} \mathrm{C}$ overnight. Kynol (ACF20) was used as received. ACF20 was also post-treated with concentrated $\mathrm{HNO}_{3}$. Under the same condition described above, and labeled as A20-NitricRT and A20-Nitric-80, respectively.

\subsection{Ammonia adsorption}

A dynamic breakthrough test has been used to evaluate the efficiency of the ACFC media for removing $\mathrm{NH}_{3}$ from air in a flow-through configuration (Fig. 1). Influent $\mathrm{NH}_{3}$ concentrations were adjusted using flow controllers and calibrated by effluent $\mathrm{NH}_{3}$ sensor 
$\left(\mathrm{NH}_{3}\right.$ electrochemical sensor, Industrial Scientific, iBrid MX6, 0-500 ppm with 1ppm resolution). Effluent $\mathrm{NH}_{3}$ concentrations were monitored using the same electrochemical sensor. ACFCs were punched to form $2.4 \mathrm{~cm}$ diameter circles with sample weight $\sim 0.3 \mathrm{~g}$ and

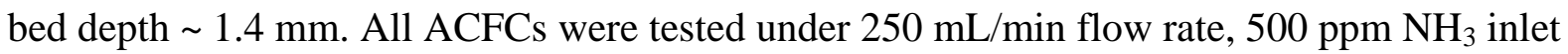
concentration and both $0 \%$ and $50 \%$ relative humidity (RH). Adsorption capacity of active media is calculated by integration of the flowthrough curve until $\mathrm{C} / \mathrm{C}_{0}=0.1(50 \mathrm{ppm})$. In order to study a special interaction mechanism, samples were thermally regenerated at 100$200{ }^{\circ} \mathrm{C}$ for $1 \mathrm{hr}$ after breakthrough.

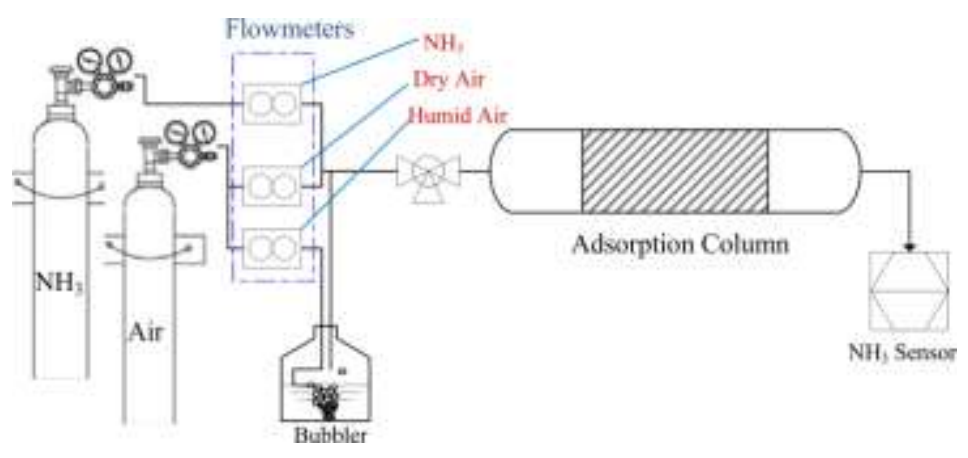

Fig. 1 Ammonia dynamic flowthrough test

\subsection{Characterizations}

SEM images were obtained using a Hitachi S-4700 with mixed field emission with a 10 $\mathrm{kV}-15 \mathrm{kV}$ accelerating voltage. Samples were attached on an aluminum sample holder using a carbon tape. Sample conductivity was improved by coating with a thin layer of metal using a gold palladium plasma.

Surface area and pore size analysis was obtained using a Quantachrome Autosorb-1 pore surface analyzer. Samples were first dried at $110{ }^{\circ} \mathrm{C}$ under vacuum before measurement. These samples were degassed until the outgassing pressure change was below $5 \mu \mathrm{m} \mathrm{Hg} / \mathrm{min}$ before analysis. $\mathrm{N}_{2}$ adsorption isotherms at $77 \mathrm{~K}$ were used to measure the surface area and pore volume. BET equation was used to calculate the surface area using $\mathrm{P} / \mathrm{P}_{0}$ range from 
0.05 to 0.3 ; The Dubinin-Radushkevitch (DR) equation was used to deduce the total micropore volume; Total pore volume was estimated from the amount of nitrogen adsorbed at $\mathrm{P} / \mathrm{P}_{0}=0.95$. Mesopore volume was calculated by the difference of total pore volume and micropore volume.

Coating contents of samples were measured by TGA (Hi-Res TA Instruments 2950 Thermogravimetric Analyzer). The coating contents of ACFCs were measured by burning off carbon coating at $800^{\circ} \mathrm{C}$ in air. Sample's coating content was calculated by the following equation:

$$
\text { Coating Content } \%=\frac{\text { Weight loss } \%\left(\text { from } 110^{\circ} \mathrm{C} \text { to } 800{ }^{\circ} \mathrm{C}\right)}{1-\text { moisture content } \%\left(\text { weight loss from RT to } 110^{\circ} \mathrm{C}\right)}
$$

Elemental analysis was used to quantify carbon, hydrogen, nitrogen and other heteroatoms presents in the carbon matrix. Chemical composition $(\mathrm{C}, \mathrm{H}$, and $\mathrm{N})$ of samples was determined using a Model CE440 Elemental Analyzer. The detection limit for each element was $0.10 \%$ with errors $0.06 \%$. Additionally, zinc $(\mathrm{Zn})$ content was determined by ICP/MS with detection limits $<1 \mathrm{ppb}$. Oxygen content was determined indirectly by the following equation:

$$
\mathrm{w}[\mathrm{O}]=\mathrm{w}[\text { coating content } \%]-\mathrm{w}[\mathrm{C}]-\mathrm{w}[\mathrm{H}]-\mathrm{w}[\mathrm{N}]-\mathrm{w}[\mathrm{Zn}]
$$

The zeta potential $(\zeta)$ of PANCAF and HACAX was measured at different equilibrium $\mathrm{pH}$ using Zetasizer Nano ZS (Malvern Instruments) to identify the isoelectric point (IEP). Samples $(\sim 10 \mathrm{mg})$ were grounded into powder, and mixed with $15 \mathrm{ml}$ aqueous solution with $\mathrm{pH}$ between 2 and 12. $\mathrm{pH}$ of solution was adjusted by adding $0.5 \mathrm{~N} \mathrm{HCl}$ or $\mathrm{NaOH}$. After shaking for $24 \mathrm{hr}$, the zeta potential of adsorbent and final $\mathrm{pH}$ of suspension was measured.

The $\mathrm{pH}$ isotherm was measured to identify point of zero charge $\mathrm{pH}(\mathrm{PZC})$, which is the $\mathrm{pH}$ when the activated carbon materials have zero net charge as total; Above which, the 
carbon is negatively charged and vice versa. This method is based on the work by LopezRaman et al.[32] with minor modifications. Samples $(\sim 10 \mathrm{mg})$ were ground into powder, and mixed with $15 \mathrm{ml}$ aqueous solution with $\mathrm{pH}$ between 2 and 12. $\mathrm{pH}$ of solution was adjusted by adding $0.5 \mathrm{M} \mathrm{HCl}$ or $\mathrm{NaOH}$ and measured by $\mathrm{pH}$ electrode. After shaking for $24 \mathrm{hrs}, \mathrm{pH}$ of the final suspension was measured by $\mathrm{pH}$ electrode. The $\mathrm{pH}$ at which $\mathrm{pH}_{\text {final }}=\mathrm{pH}_{\text {initial }}$ or plateau is determined as PZC.

Infrared spectrum was obtained by Thermo Nicolet Nexus 670 FTIR to identify chemical functional groups. As activated carbon samples are intrinsic absorbers, DRIFTs (Diffuse Reflectance Infrared Fourier Transform Spectroscopy) mode is applied to maximize signal intensity. Fibrous samples were directly measured without $\mathrm{KBr}$ addition. Data acquisition was performed by Omnic ${ }^{\circledR}$ software with 32 scans at a resolution of $4 \mathrm{~cm}^{-1}$.

Boehm titration with minor changes[33-36] was employed to quantify surface acidic oxygen functional groups into phenolic, lactonic, and carboxylic acid functional groups within activated carbon (the detailed procedure is described in ESI).

\section{Results and discussion}

\subsection{Physical properties}

SEM images presented in Fig. 2 show the textures of different samples. ACF20 has fiber diameter $\sim 13 \pm 5 \mu \mathrm{m}$ densely packed in a woven pattern; $\mathrm{HNO}_{3}$ treatment either at room temperature and $80{ }^{\circ} \mathrm{C}$ did not cause noticeable changes at the micron scale. All ACFCs are composed of active coatings and glass fiber substrates. The original glass fiber is $\sim 6.5 \mu \mathrm{m}$ in diameter and loosely packed. Activated layers are either coated uniformly on glass fiber or as bridging in-between fibers. Same as that for ACF20, there are no obvious geometry changes after $\mathrm{HNO}_{3}$ treatment, suggesting that oxidation by $\mathrm{HNO}_{3}$ will not affect mechanical integrity. 


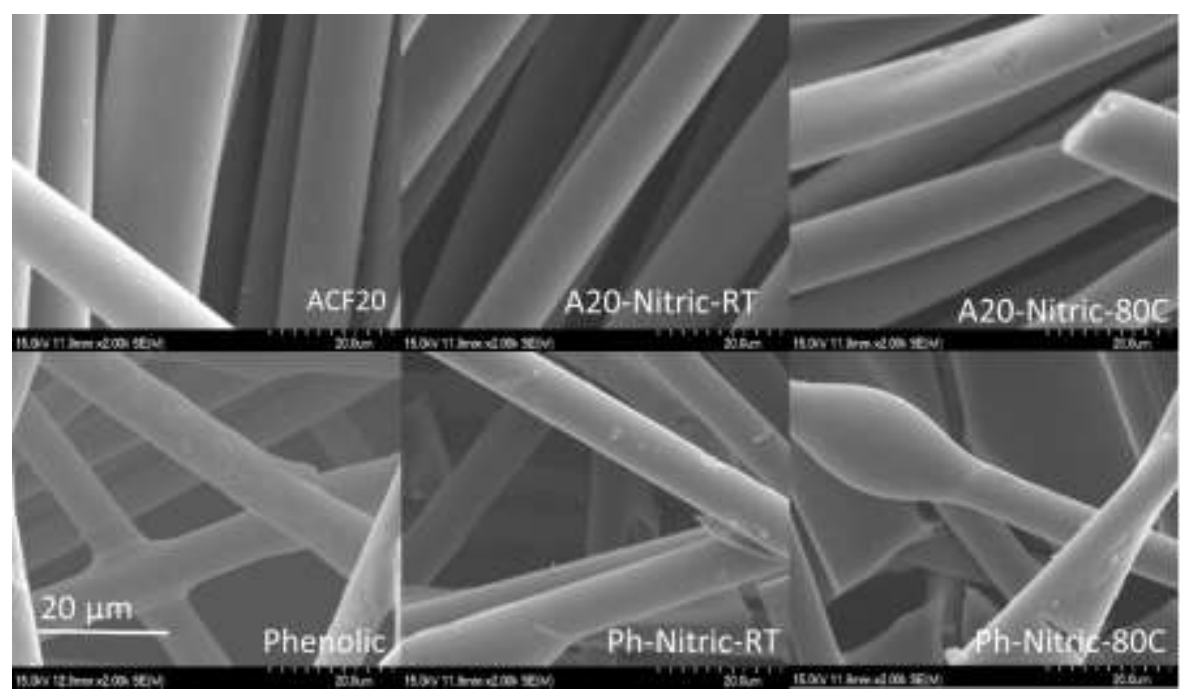

Fig. 2 SEM image of ACFCs and ACF and oxidation derivatives

Coating content and pore size analysis are summarized in Table 1. Compared with ACFs materials which are pure carbon, coating content of ACFCs are controlled between 30 to $50 \%_{\mathrm{wt}}$ to keep reasonable amount of active coating layers without introducing tremendous pressure drop. Coating content is essential to leveraging capacity, pressure drop and cost for specific applications; in light of that, most of the parameters are calculated and compared based on coating as opposed to the total materials. High surface area and porosity are essential to providing more accessible functional groups and thus adsorption efficiency[37]. Most ACFCs are microporous (> 90\%), and have relatively high surface area values (> 1000 $\mathrm{m}^{2} / \mathrm{g}$ based on coating); micropores are critical for removal of trace contaminants due to the higher overlap in potential from the van der Waal forces of opposite pore walls[8]. Posttreatment with nitric acid has little effect on surface area of samples, except the phenolic based ACFCs treated with $\mathrm{HNO}_{3}$ at $80{ }^{\circ} \mathrm{C}$ (Ph-Nitric-80C), where the material underwent degradation and/or blockage of the pore structure. It may be due to the incomplete carbonization of chemical activation, which leads to relatively unstable structure compared with materials obtained from physical activation[38]. 
Table 1 Coating Content, Surface Area and Pore Analysis

\begin{tabular}{|c|c|c|c|c|c|c|}
\hline Material & $\begin{array}{c}\text { Coating } \\
(\% \text { wt })\end{array}$ & $\begin{array}{c}\text { BET } \\
\left(\mathrm{m}^{2} / \mathrm{g}\right)\end{array}$ & $\begin{array}{c}\text { BET- } \\
\text { Coating } \\
\left(\mathrm{m}^{2} / \mathrm{g}\right)\end{array}$ & $\begin{array}{c}\text { Micro-pore } \\
\left(\mathrm{cm}^{3} / \mathrm{g}\right)\end{array}$ & $\begin{array}{c}\text { Meso-pore } \\
\left(\mathrm{cm}^{3} / \mathrm{g}\right)\end{array}$ & $\begin{array}{c}\text { Micro- } \\
\text { pore Ratio } \\
(\%)\end{array}$ \\
\hline ACF20 [39] & $>99$ & 1843 & 1843 & 0.62 & 0.02 & 96 \\
\hline A20-Nitric-RT & $>99$ & 2375 & 2375 & 1.28 & 0.02 & 98 \\
\hline A20-Nitric-80C & $>99$ & 2428 & 2428 & 1.3 & 0.04 & 97 \\
\hline Phenolic & 47 & 608 & 1294 & 0.33 & 0.04 & 89 \\
\hline Ph-Nitric-RT & 53 & 688 & 1310 & 0.35 & 0.04 & 90 \\
\hline Ph-Nitric-80C & 53 & 213 & 402 & 0.11 & 0.02 & 85 \\
\hline
\end{tabular}

\subsection{Surface chemistry properties}

Surface chemistry - in particular the density and type of oxygen functional groups-is of paramount importance for $\mathrm{NH}_{3}$ adsorption in activated carbons[8, 40]. One potential means of introducing oxygen groups including carboxylic, phenolic and lactonic sites is by oxidization of carbonaceous materials using nitric acid[15]. These functional groups can potentially greatly improve $\mathrm{NH}_{3}$ adsorption capacity.

Given that the importance surface chemistry plays for successful adsorbents design for $\mathrm{NH}_{3}$, several techniques, including elemental analysis, FTIR, $\mathrm{pH}$ isotherm, zeta potential and Boehm titration were employed to explore surface chemistry from different perspectives.

According to previous literature, a critical design parameter for high capacity adsorbents is the $\mathrm{O} / \mathrm{C}$ ratio[12], which is indirectly related to the number of acidic groups present in the pore structure. Higher oxygen content is also commonly regarded as the major reason for high $\mathrm{NH}_{3}$ adsorption capacity[12, 13]. Key ACFC elemental analysis results are shown in Table 2. While original ACF20 showed only 5\% O/C, nitric acid treatment greatly increased oxygen content on the surface, with 3-fold and 10-fold increases for room temperature and high temperature treatment, respectively. Original Phenolic ACFCs have more oxygen on 
surface than ACF20 due to incomplete carbonization during chemical activation, and posttreatment improves $\mathrm{O} / \mathrm{C}$ to $35 \%$ and $61 \%$, which are each higher than ACFs treated under the same conditions, respectively.

Table 2 Elemental Analysis Results based on coating (\%wt)

\begin{tabular}{|l|l|l|l|l|l|l|}
\hline Materials & $\mathrm{C}$ & $\mathrm{H}$ & $\mathrm{N}$ & $\mathrm{O}$ & $\mathrm{Zn}$ & $\mathrm{O} / \mathrm{C}$ \\
\hline ACF20 & $94 \%$ & $0.4 \%$ & $0.3 \%$ & $5 \%$ & - & $5 \%$ \\
\hline A20-Nitric-RT & $84 \%$ & $0.4 \%$ & $1.0 \%$ & $14 \%$ & - & $17 \%$ \\
\hline A20-Nitric-80C & $66 \%$ & $1.2 \%$ & $0.7 \%$ & $32 \%$ & - & $49 \%$ \\
\hline Phenolic & $88 \%$ & $2.0 \%$ & $0.0 \%$ & $10 \%$ & $1 \%$ & $12 \%$ \\
\hline Ph-Nitric-RT & $71 \%$ & $1.3 \%$ & $1.9 \%$ & $26 \%$ & $0 \%$ & $36 \%$ \\
\hline Ph-Nitric-80C & $60 \%$ & $1.6 \%$ & $2.4 \%$ & $36 \%$ & - & $61 \%$ \\
\hline
\end{tabular}

FTIR in DRIFTS mode was used to further study surface functional groups[38, 41]. FTIR spectra of ACFs are shown in Fig. 3. The peaks at $\sim 1600 \mathrm{~cm}^{-1}$ could be assigned to $\mathrm{C}=\mathrm{C}$ in the skeletal carbon matrix[42] for the original ACF20; however, peak position shifts towards higher frequency (i.e., towards $1650 \mathrm{~cm}^{-1}$ ) upon oxidation by nitric acid at both $\mathrm{RT}$ and $80{ }^{\circ} \mathrm{C}$, possibly suggesting the formation of more conjugated $\mathrm{C}=\mathrm{O}$ due to carbonyl[43] or quinone[44] functional groups. Small peaks from 1740-1680 $\mathrm{cm}^{-1}$ suggest the presence of $\mathrm{C}=\mathrm{O}$ related to lactone and/or carboxylic acid structures[45, 46]. A prominent peak at 1772 $\mathrm{cm}^{-1}$ for A20-Nitric-80 may suggest the presence of a significant amount of carbonyl groups including a mixture of carboxylic acid, lactone, and especially anhydride functional groups[47]. Peaks from 1390-1340 $\mathrm{cm}^{-1}$ might be due to phenol or nitro groups [13, 45, 46, 48]. These peaks are more pronounced in the more oxidized samples. The FTIR spectra confirmed the presence of acidic groups on the surface of these carbon fibers. 


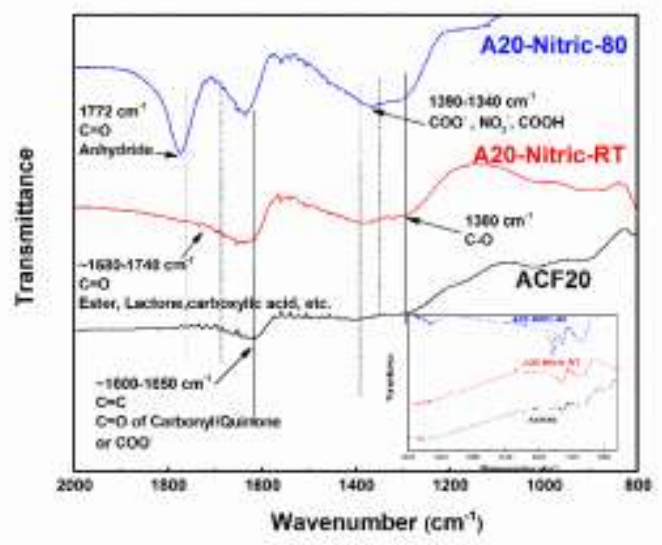

Fig. 3 FTIR of ACFs Series samples

Phenolic ACFCs FTIR spectra are shown in Fig. 4. Peaks at $\sim 1600 \mathrm{~cm}^{-1}$ suggest stable polyaromatic $C=C[42]$. Upon nitric acid oxidation, the peak near $1700 \mathrm{~cm}^{-1}$ both increased in intensity and broadened from $1706 \mathrm{~cm}^{-1}$ to $1760-1694 \mathrm{~cm}^{-1}$, and $1773-1697 \mathrm{~cm}^{-1}$ for original, RT treatment, and $80{ }^{\circ} \mathrm{C}$ treatment respectively. This suggests the introduction of a variety of functional groups including carboxylic acid, lactonic[49], carbonyl or quinones[13], etc. Especially with the $80{ }^{\circ} \mathrm{C}$ treatment, peaks above $1750 \mathrm{~cm}^{-1}$ may suggest the formation of anhydrides[13, 47]. Additionally, more pronounced peaks at $3400 \mathrm{~cm}^{-1}$ and $1040 \mathrm{~cm}^{-1}$ suggest a greatly increased amount of carboxylic acid groups integrated in the matrix.

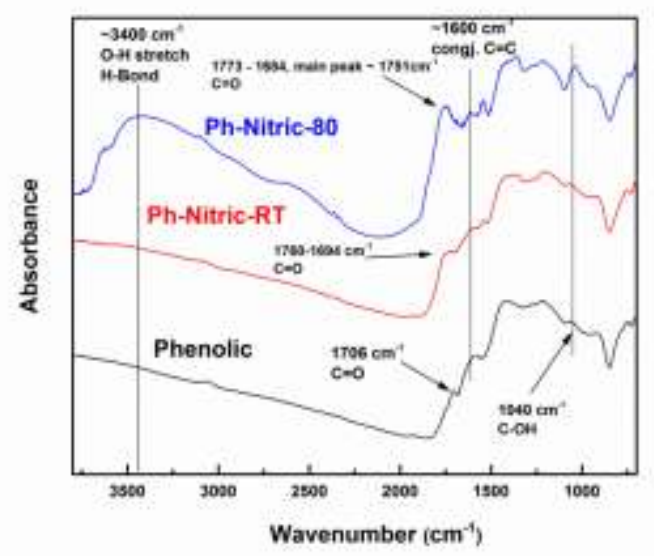

Fig. 4 FTIR of ACFCs 
Boehm titration was employed in order to quantify distribution of surface acidic functional groups amongst 3 main types: phenolic-, lactonic- and carboxylic acid-class groups (Fig. 5). Original ACF20 has a very limited amount of total surface acidic functional groups $(0.2 \mathrm{mmol} / \mathrm{g})$. RT treatment in nitric acid introduces phenolic, lactonic and carboxylic acid functional groups, while increasing total acidic functional groups 4.5 -fold. Upon high temperature nitric acid treatment, most phenolic and lactonic functional groups have disappeared, while many more carboxylic acid functional groups $(1.2 \mathrm{mmol} / \mathrm{g})$ are introduced. It should be noted that Boehm titration method cannot distinguish anhydride with carboxylic acid, thus $1.2 \mathrm{mmol} / \mathrm{g}$ includes both since FTIR suggests the presence of anhdyrides.

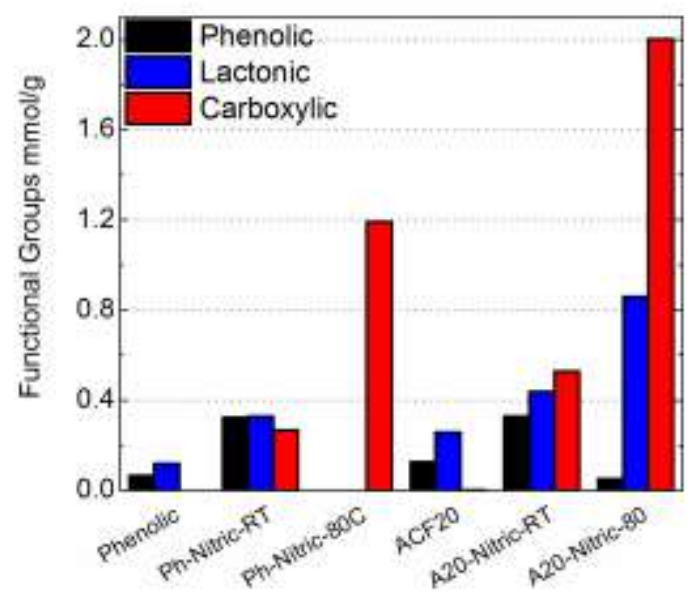

Fig. 5 Surface acidic functional groups identified by Boehm titration

Original phenolic ACFCs showed improved concentration of acid functional groups compared with ACF20 but are still limited to $~ 0.4 \mathrm{mmol} / \mathrm{g}$. RT treatment in nitric acid primarily introduces phenolic and carboxylic acid groups while increasing total acidic functional groups 3-fold. After high temperature nitric acid treatment, carboxylic acid functional groups including anhydrides increase to $2 \mathrm{mmol} / \mathrm{g}$. Complete speciation of surface oxygen cannot be achieved through Boehm titration as it is limited in that it cannot probe neutral oxygen functionalities: ketones, aldehydes, esters, ethers, etc. Additionally, wet 
chemistry may not able to probe functionalities in ultra-small pores where hydrated ions cannot enter, such as the present case where hydrated $\mathrm{Na}^{+}$cannot get into pores smaller than $7.4 \AA ̊ 50]$.

IEP and PZC are important measurement of the $\mathrm{pH}$ associated with net neutral surface and total charge, respectively. At $\mathrm{pH}<$ IEP or PZC, sample surfaces and bulk are positively charged; conversely, at pH > IEP or PZC, surface and bulk are negatively charged. IEP or PZC values each depend on the type and amount of functional groups. IEP or PZC lower than 7 tends to indicate activated carbons rich in acidic functional groups[41]. Lower values indicate increasing acidic functional groups/strength on surface[51]. Compared with IEP which only represents external surface, PZC represents the whole surface both internally and externally. Thus, differences between PZC and IEP reveal the distribution of charge and thus functional groups on the internal and external surface of porous carbons[41]. PZC and IEP of the ACFCs and ACFs are summarized in Table 3. For both ACF20 and phenolics, PZC $\sim 7$ of the original samples suggests the original materials are almost neutral as a bulk. After $\mathrm{HNO}_{3}$ oxidation treatment, both PZC and IEP are decreased, suggesting that acidic functional groups were preferentially introduced on the surface. The difference between PZC and IEP shows non-uniformity between internal and external surfaces; the present results suggest external surfaces are more oxidized for all samples, which in turn suggests XPS may not be appropriate for quantification of functional groups of all samples. Higher temperature nitric acid treatment not only introduced more acidic functional groups but also showed more uniform oxidation compared with RT oxidation. 
Table $3 \mathrm{pH}$ of point of zero charge and $\mathrm{pH}$ of isoelectric point

\begin{tabular}{|c|c|c|c|c|}
\hline & Sample & $\mathrm{pH}_{\mathrm{PZC}}$ & $\mathrm{pH}_{\mathrm{IEP}}$ & $\mathrm{pH}_{\mathrm{PZC}}-\mathrm{pH}_{\mathrm{IEP}}$ \\
\hline \multirow{3}{*}{ ACFs Series } & ACF20 & 7.2 & 3.6 & 3.6 \\
\cline { 2 - 5 } & A20-Nitric-RT & 6.5 & 2.7 & 3.8 \\
\cline { 2 - 5 } & A20-Nitric-80 & 4.5 & 1 & 3.5 \\
\hline \multirow{3}{*}{ ACFCs Series } & Phenolic & 7.2 & 2.8 & 4.4 \\
\cline { 2 - 5 } & Ph-Nitric-RT & 6.6 & 1.8 & 4.8 \\
\cline { 2 - 5 } & Ph-Nitric-80 & 4.9 & $<1$ & $>3.9$ \\
\hline
\end{tabular}

\subsection{Ammonia adsorption}

Dynamic breakthrough tests were employed to evaluate the efficiency of the ACFCs media for removing $\mathrm{NH}_{3}$ from air in a flow-through configuration. The results are summarized in Fig. 6, with breakthrough curves in supplementary information (ESI). For ACFs samples, unmodified ACF20 has a capacity of only $\sim 1 \mathrm{mg} / \mathrm{g}$. A20-Nitric-RT has an adsorption capacity of $\sim 10 \mathrm{mg} / \mathrm{g}$ due to increased surface acidic groups introduced by oxidation; $80{ }^{\circ} \mathrm{C} \mathrm{HNO}_{3}$ treatment exhibited more than double the sorption capacity at both $0 \%$ and 50\% RH conditions, relative to RT treatment. Moisture plays an important role in adsorption capacity — either positive or negative depending on the circumstances. A20-NitricRT showed $66 \%$ more capacity under humid conditions compared with $0 \%$ RH conditions. This increase could be caused by improved surface acidity and thus hydrophilicity of materials, which increases moisture adsorption; thin layers of adsorbed water are known to promote adsorption of $\mathrm{NH}_{3}$ by dissolution effects[8]. As for A20-Nitric-80, on the contrary, capacities under humid conditions are $40 \%$ lower than dry conditions. This may be due to excessive water adsorbed on the highly acidic surface under humid condition, which could clog the pores and prohibit diffusion of ammonia to active sites [10]. Another possibility is 
that hydrated $\mathrm{NH}_{3}(\sim 5.3 \AA[50])$ is too large to access the ultrafine pores, or is simply limited by kinetics when a large amount of water has accumulated on the surface.

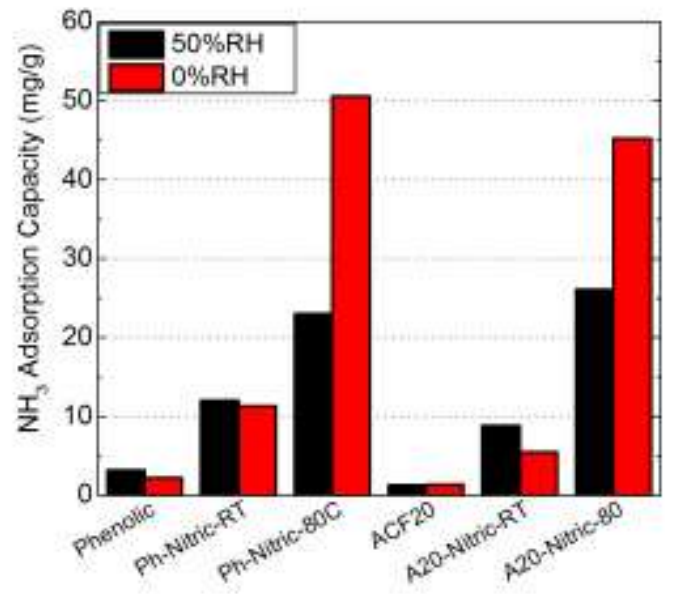

Fig. 6 Ammonia dynamic adsorption capacity under $0 \%$ and $50 \%$ relative humidity

For phenolic ACFCs, the original sample shows slightly better capacity $(\sim 2 \mathrm{mg} / \mathrm{g})$ compared with ACF20. This could be explained by the incomplete carbonization of phenolic ACFCs which provide residual acidic functional groups at a level 4 times higher than ACF20 as suggested by Boehm titration. Ph-Nitric-RT has a sorption capacity of $\sim 10 \mathrm{mg} / \mathrm{g} ; 80{ }^{\circ} \mathrm{C}$ $\mathrm{HNO}_{3}$ treatment exhibited at least double the sorption capacity at both $0 \%$ and $50 \% \mathrm{RH}$ conditions relative to RT treatment. The effect of humidity on capacity follows the same trend as with the series of ACFs samples.

ACFCs and ACFs series each follow similar trends, with acid treatment greatly improving adsorption capacity. RT-nitric acid treatment increased capacity by 4-fold to 6fold; high temperature nitric acid treatment increased capacity by an order of magnitude; moreover, the trends coincide with the amount surface acidic functional groups determined by Boehm titration and elemental analysis. 


\subsection{Mechanism of anhydride-ammonia interaction}

Mechanisms of interaction between $\mathrm{NH}_{3}$ and various surface functional groups merit specific evaluation. $\mathrm{NH}_{3}$ can be adsorbed on and interact with the surface through various mechanisms, roughly categorized into: non-specific van der Waals force, dissolution in water film adsorbed on surface, hydrogen bonding, Brønsted acid-base interactions (mainly carboxylic acid sites via ammonium ions)[12, 13]. In this study, another distinct mechanism was discovered, involving Brønsted acid-base interactions and contributing a higher amount of adsorbed $\mathrm{NH}_{3}$.

Both Ph-Nitric-80 and A20-Nitric-80 showed a broad range of acidic functional groups in their FTIR spectra. The peak at $1750-1800 \mathrm{~cm}^{-1}$ suggests the formation of anhydride due to aggressive oxidation by $\mathrm{HNO}_{3}$ at high temperature. In order to further explore the interactions with $\mathrm{NH}_{3}$, FTIR of original samples and samples treated with $\mathrm{NH}_{3}$ were compared.

For A20-Nitric-80, as shown in Fig. 7, the original sample has an intense peak at 1773 $\mathrm{cm}^{-1}$ suggesting the presence of anhydride functional groups. After treatment with $\mathrm{NH}_{3}$, the peak at $1773 \mathrm{~cm}^{-1}$ shifted to $1734 \mathrm{~cm}^{-1}$ indicating the possible formation of $\mathrm{COOH}$ from the anhydride. Increased intensity at $1635 \mathrm{~cm}^{-1}$ may imply the formation of amide bonds[52]; peaks at $1535 \mathrm{~cm}^{-1}$ and $1370 \mathrm{~cm}^{-1}$ suggest the formation of $\mathrm{COO}^{-}$[12]. After thermal regeneration, the peak at $1774 \mathrm{~cm}^{-1}$ reappeared, along with a small peak at $1717 \mathrm{~cm}^{-1}$, implying the possible formation of imide bonds[52]. 


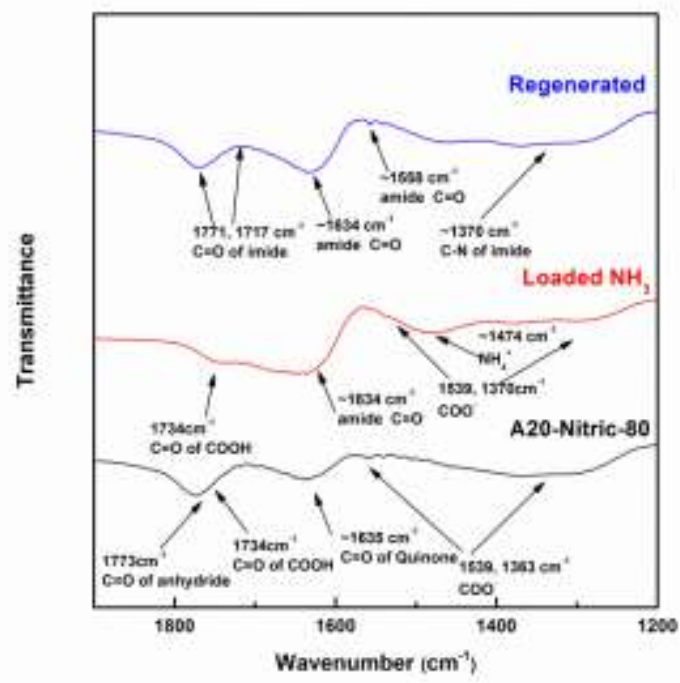

Fig. 7 FTIR of A20-Nitric-80, loaded with $\mathrm{NH}_{3}$ and regenerated

For Ph-Nitric-80, the same trend is also observed by FTIR. As shown in Fig.8, after treatment with $\mathrm{NH}_{3}$, the increased intensity at 1439 and $1400 \mathrm{~cm}^{-1}$ suggests the presence of $\mathrm{NH}_{4}{ }^{+}$, and a peak shift from 1773-1684 to $1710-1650 \mathrm{~cm}^{-1}$ suggests a change from $\mathrm{COOH}$ and $\mathrm{O}=\mathrm{C}-\mathrm{O}-\mathrm{C}=\mathrm{O}$ into $\mathrm{COO}$. Peaks at 1657 and $1562 \mathrm{~cm}^{-1}$ suggest the formation of amide bonds. After regeneration, the peak at $1774 \mathrm{~cm}^{-1}$ reappeared, along with a new peak at 1722 $\mathrm{cm}^{-1}$, which may also suggest the formation of imide bonds. In the absence of strong acid or base, neither imides nor amides are generally regenerable under the mild heating conditions tested[53]. 


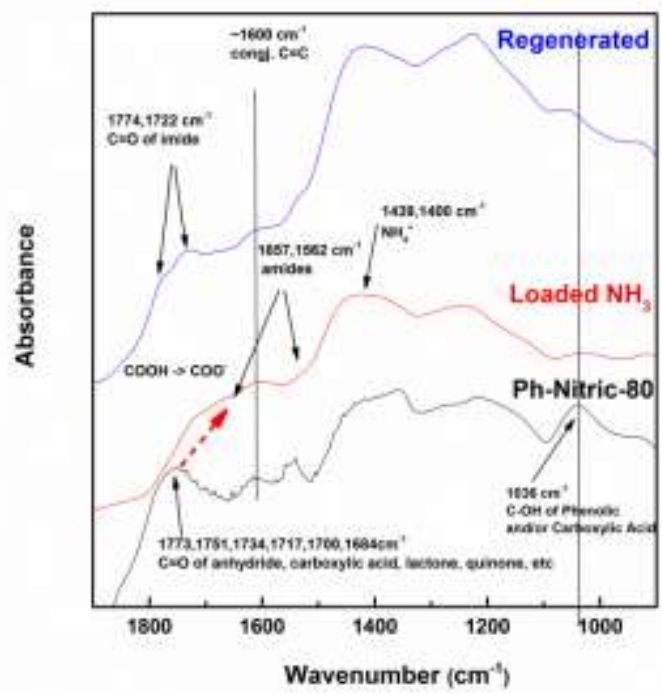

Fig. 8 FTIR of original Ph-Nitric-80, treated with $\mathrm{NH}_{3}$ and regenerated sample

The interactions between anhydride functional group and ammonia are illustrated in Fig. 9. Whether the final product stays in amide or imide form is greatly influenced by the presence of water. In the absence of water, reactions should be driven more towards formation of imide bond; conversely, with water present in more humid conditions, the reactions would tend towards formation of amide and carboxylate anion-ammonium cation pairs. Typically, Brønsted acid-base interactions are reversible, while amide or imide bonds are irreversible in the absence of a catalyst. Humid conditions should favor amide and COONH4 pair formation, in which case $50 \%$ of initial capacity could be recovered after regeneration by heating; on the other hand, sorption at $0 \% \mathrm{RH}$ should tend to yield more imides — which would be completely irreversible and necessarily lead to $<50 \%$ regeneration efficiency. Indeed, we see this pattern (i.e., $50 \%$ regeneration efficiency at $50 \% \mathrm{RH}$, and $<50 \%$ at $0 \% \mathrm{RH}$ condition[54]) in the regeneration tests for the samples anticipated to have the highest anhydride content: A20-Nitric-80 and Phenolic-Nitric-80. Collectively, these results support the FTIR finding of anhydrides upon high temperature nitric acid treatment. 


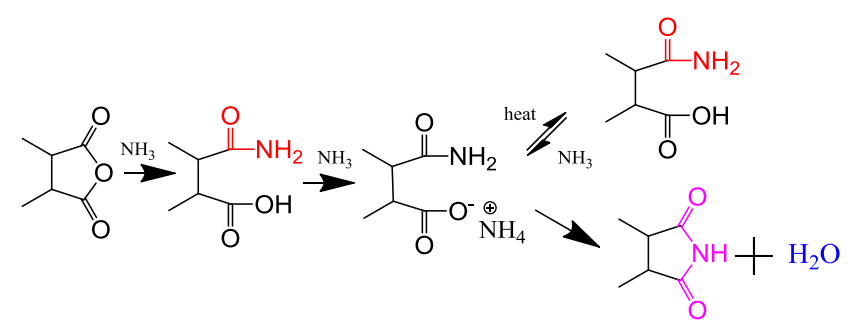

Fig. 9 Mechanism of $\mathrm{NH}_{3}$ interaction with anhydride functional group

\subsection{Correlation between surface functional groups and capacity}

In order to analyze which functional group(s) play the key role in adsorption capacity, the sample capacity and measured amount of functional groups have been summarized and converted to equivalent units (mmol/g), as shown in Table 4.

Table 4 Summary of surface functional groups vs. adsorption capacities and regenerated capacities

\begin{tabular}{|c|c|c|c|c|c|}
\hline \multirow{2}{*}{ Sample } & \multicolumn{3}{|c|}{$\mathrm{x} \mathrm{mmol/g}$} & \multicolumn{2}{c|}{$\mathrm{y} \mathrm{mmol/g}$} \\
\cline { 2 - 6 } & Phenolic & Lactonic & $\begin{array}{c}\text { Carboxylic } \\
\text { Acid }\end{array}$ & $\begin{array}{c}\text { Capacity } \\
0 \% \mathrm{RH}\end{array}$ & $\begin{array}{c}\text { Capacity } \\
50 \% \mathrm{RH}\end{array}$ \\
\hline ACF20 & 0.06 & 0.12 & 0.00 & 0.1 & 0.1 \\
\hline A20-Nitric-RT & 0.32 & 0.33 & 0.27 & 0.3 & 0.5 \\
\hline A20-Nitric-80 & 0.00 & 0.00 & 1.19 & 2.7 & 1.5 \\
\hline Phenolic & 0.13 & 0.26 & 0.00 & 0.1 & 0.2 \\
\hline Ph-Nitric-RT & 0.33 & 0.44 & 0.53 & 0.7 & 0.7 \\
\hline Ph-Nitric-80 & 0.05 & 0.86 & 2.00 & 3.0 & 1.4 \\
\hline
\end{tabular}

Correlation coefficient $r$ and significance testing $p$-value were computed using Matlab (Table 5). The correlation coefficient $r$ is a measurement of linear dependence between two variables $\mathrm{X}$ and $\mathrm{Y}$. The $p$-value is employed for testing the hypothesis of no correlation against the alternative that there is a nonzero correlation. If the p-value is less than 0.05 , or more strictly 0.01 , then the correlation between $\mathrm{X}$ and $\mathrm{Y}$ is significant. 
Table 5 Correlation coefficient $r$ and $p$-value of different surface functional groups and capacities

\begin{tabular}{|l|l|l|l|l|}
\hline & \multicolumn{2}{|l|}{ Dry-Capacity } & \multicolumn{2}{l|}{ Wet-Capacity } \\
\hline & $\mathrm{r}$ & $\mathrm{p}$ & $\mathrm{r}$ & $\mathrm{p}$ \\
\hline Phenolic & -0.551 & 0.257 & -0.375 & 0.464 \\
\hline Lactonic & 0.355 & 0.490 & 0.299 & 0.565 \\
\hline Carboxylic & $0.961^{* *}$ & 0.002 & $0.921^{* *}$ & 0.009 \\
\hline
\end{tabular}

The results demonstrate that phenolic- and lactonic-class functional groups are less correlated with dynamic adsorption capacity. On the other hand, carboxylic acid-class groups - anhydrides included therein — are strongly correlated with high adsorption capacity. Results suggest that carboxylic acid-class functional groups exhibit a significant influence on high dynamic adsorption capacity. Conversely, phenolic- and lactonic-class functional groups are less significant for adsorption capacity.

\section{Conclusions}

In this work, activated carbon fiber composites (ACFCs) were developed for removal of ammonia from air. Kynol based ACFs modified by oxidation, and both original and oxidized ACFCs possess a large density of surface acidic functional groups and thus high $\mathrm{NH}_{3}$ adsorption capacity. High surface area $>1000 \mathrm{~m}^{2} / \mathrm{g}$ observed in all ACFCs is essential to providing more accessible surface functional groups and consequently adsorption efficiency. Surface characterization showed that surface acidic oxygen groups, in particular carboxylic acid and/or anhydrides, play the key role in both adsorption capacity and regeneration efficiency. Reaction of anhydrides with ammonia results in formation of non-regenerable amide and/or imide units, indicating the possibility for high temperature ammonia adsorption. 
Compared with traditional physical activation, where harsh activating conditions result in a low number of heteroatoms and fewer surface functionalities[30], chemical activation may serve to retain a rich distribution of surface functional groups originated from a precursor, which could in turn prove effective for polar pollutants like $\mathrm{NH}_{3}$.

\section{Acknowledgements}

The authors would like to thank the financial support provided by Department of Materials Science and Engineering at University of Illinois at Urbana-Champaign. The authors would also like to thank the financial support by DoD Army under the subcontract W9132T-12-C-0008. SEM were carried out in the Center for Microanalysis of Materials, University of Illinois, which is partially supported by the US Department of Energy under grant DEFG02-91-ER45439. We thank Rudi Laufhutte for elemental analysis in the Microanalysis Laboratory in the University of Illinois. Additionally, we thank Rich Hassch for insightful discussion on XPS peak deconvolutions and interpretations. The first author would like to thank Camille Petit (currently at Imperial College London) for her very helpful suggestions and advice on experiment setup at the very beginning of this project. The first author also thanks Ying Guo (University of Illinois Urbana-Champaign, Psychology Department) for advice and statistical analysis.

\section{References}

[1] S. Rowley, J. Yang, A. Wei, Reducing capital and labor costs of 193nm lithography monitoring of airborne molecular contamination (AMC) through proactive assessment and implementation of AMC monitoring techniques and strategies, Lithography Asia 2008, SPIE, Taipei, Taiwan, 2008, pp. 71400U-71400U-71409.

[2] M. Katz, G.A. Gruver, H.R. Kunz, Regenerable ammonia scrubber, Google Patents, Canada, 1981.

[3] J. James, Spacecraft Maximum Allowable Concentrations for Airborne Contaminants, NASA, NASA, 2008. 
[4] M. Bennett, TICs, TIMs, and Terrorists, Today's Chemist at Work, (2003) 21.

[5] G. Peterson, C. Karwacki, J. Rossin, Novel Collective Protection Filters for Emerging TIC Requirements: Axial and Radial-Flow Filter Designs, Edgewood Chemical Biological Center2007.

[6] B. Nielsen, DoD Collective Protection Research and Development Program, NBC Defense Collective Protection Conference, Orlando, Florida 2002.

[7] FEMA, Safe Rooms and Shelters: Protecting People Against Terrorist Attacks, 2006.

[8] T.J. Bandosz, Towards understanding reactive adsorption of small molecule toxic gases on carbonaceous materials, Catal. Today, (2011).

[9] J.B. DeCoste, G.W. Peterson, Metal-Organic Frameworks for Air Purification of Toxic Chemicals, Chem. Rev., 114 (2014) 5695-5727.

[10] C. Petit, Factors affecting the removal of ammonia from air on carbonaceous materials Investigation of reactive adsorption mechanism, Department of Chemistry, City University of New York2011.

[11] C. Canals-Batlle, A. Ros, M.A. Lillo-Ródenas, E. Fuente, M.A. Montes-Morán, M.J. Martin, A. Linares-Solano, Carbonaceous adsorbents for NH3 removal at room temperature, Carbon, 46 (2008) 176-178.

[12] M. Gonçalves, L. Sánchez-García, E.D. Oliveira Jardim, J. Silvestre-Albero, F. Rodríguez-Reinoso, Ammonia removal using activated carbons: Effect of the surface chemistry in dry and moist conditions, Environ. Sci. Technol., 45 (2011) 10605-10610.

[13] C.C. Huang, H.S. Li, C.H. Chen, Effect of surface acidic oxides of activated carbon on adsorption of ammonia, J. Hazard. Mater., 159 (2008) 523-527.

[14] C.L. Mangun, R.D. Braatz, J. Economy, A.J. Hall, Fixed bed adsorption of acetone and ammonia onto oxidized activated carbon fibers, Ind. Eng. Chem. Res., 38 (1999) 3499-8504.

[15] C.L. Mangun, K.R. Benak, M.A. Daley, J. Economy, Oxidation of activated carbon fibers: Effect on pore size, surface chemistry, and adsorption properties, Chem. Mater., 11 (1999) 3476-3483.

[16] M. Molina-Sabio, M. Gonalves, F. Rodríguez-Reinoso, Oxidation of activated carbon with aqueous solution of sodium dichloroisocyanurate: Effect on ammonia adsorption, Microporous Mesoporous Mater., 142 (2011) 577-584.

[17] L.M. Le Leuch, T.J. Bandosz, The role of water and surface acidity on the reactive adsorption of ammonia on modified activated carbons, Carbon, 45 (2007) 568-578.

[18] C. Petit, T.J. Bandosz, Removal of ammonia from air on molybdenum and tungsten oxide modified activated carbons, Environ. Sci. Technol., 42 (2008) 3033-3039.

[19] C. Petit, T.J. Bandosz, Complexity of ammonia interactions on activated carbons modified with V2O5, J. Colloid Interface Sci., 325 (2008) 301-308.

[20] C. Petit, T.J. Bandosz, Activated carbons modified with aluminium-zirconium polycations as adsorbents for ammonia, Microporous Mesoporous Mater., 114 (2008) 137147.

[21] C. Petit, C. Karwacki, G. Peterson, T.J. Bandosz, Interactions of ammonia with the surface of microporous carbon impregnated with transition metal chlorides, Journal of Physical Chemistry C, 111 (2007) 12705-12714.

[22] T.J. Bandosz, C. Petit, On the reactive adsorption of ammonia on activated carbons modified by impregnation with inorganic compounds, J. Colloid Interface Sci., 338 (2009) 329-345. 
[23] C.C. Rodrigues, D. de Moraes Jr, S.W. da Nóbrega, M.G. Barboza, Ammonia adsorption in a fixed bed of activated carbon, Bioresour. Technol., 98 (2007) 886-891.

[24] C. Petit, T.J. Bandosz, Role of surface heterogeneity in the removal of ammonia from air on micro/mesoporous activated carbons modified with molybdenum and tungtsen oxides, Microporous Mesoporous Mater., 118 (2009) 61-67.

[25] NIOSH, Guidance for Filtration and Air-Cleaning Systems to Protect Building Environments from Airborne Chemical, Biological, or Radiological Attacks, 2003.

[26] M. Suzuki, Activated carbon fiber: Fundamentals and applications, Carbon, 32 (1994) $577-586$.

[27] J. Economy, M. Daley, C. Mangun, Activated carbon fibers - past, present, and future, ACS Division of Fuel Chemistry, Preprints, 41 (1996) 321-324.

[28] P. Le Cloirec, Adsorption onto Activated Carbon Fiber Cloth and Electrothermal Desorption of Volatile Organic Compound (VOCs): A Specific Review, Chin. J. Chem. Eng., 20 (2012) 461-468.

[29] A.L. Cukierman, Development and Environmental Applications of Activated Carbon Cloths, ISRN Chemical Engineering, 2013 (2013) 31.

[30] K.J. Lee, J. Miyawaki, N. Shiratori, S.H. Yoon, J. Jang, Toward an effective adsorbent for polar pollutants: Formaldehyde adsorption by activated carbon, J. Hazard. Mater., 260 (2013) 82-88.

[31] Z. Yue, C.L. Mangun, J. Economy, Preparation of fibrous porous materials by chemical activation: 1 . $\mathrm{ZnCl}_{2}$ activation of polymer-coated fibers, Carbon, 40 (2002) 1181-1191.

[32] M.V. Lopez-Ramon, F. Stoeckli, C. Moreno-Castilla, F. Carrasco-Marin, On the characterization of acidic and basic surface sites on carbons by various techniques, Carbon, 37 (1999) 1215-1221.

[33] H.P. Boehm, Chemical Identification of Surface Groups, in: H.P. D.D. Eley, B.W. Paul (Eds.) Advances in Catalysis, Academic Press1966, pp. 179-274.

[34] S.L. Goertzen, K.D. Thériault, A.M. Oickle, A.C. Tarasuk, H.A. Andreas, Standardization of the Boehm titration. Part I. CO2 expulsion and endpoint determination, Carbon, 48 (2010) 1252-1261.

[35] Y.S. Kim, S.J. Yang, H.J. Lim, T. Kim, K. Lee, C.R. Park, Effects of carbon dioxide and acidic carbon compounds on the analysis of Boehm titration curves, Carbon, 50 (2012) 15101516.

[36] A.M. Oickle, S.L. Goertzen, K.R. Hopper, Y.O. Abdalla, H.A. Andreas, Standardization of the Boehm titration: Part II. Method of agitation, effect of filtering and dilute titrant, Carbon, 48 (2010) 3313-3322.

[37] D. Hulicova-Jurcakova, M. Seredych, G.Q. Lu, T.J. Bandosz, Combined effect of nitrogen- and oxygen-containing functional groups of microporous activated carbon on its electrochemical performance in supercapacitors, Adv. Funct. Mater., 19 (2009) 438-447.

[38] H. Marsh, Activated Carbon, ELSEVIER2006.

[39] C. Pelekani, V.L. Snoeylink, The importantce of micropore size in eliminating competitive adsorption.

[40] Y. Corre, M. Seredych, T.J. Bandosz, Analysis of the chemical and physical factors affecting reactive adsorption of ammonia on graphene/nanoporous carbon composites, Carbon, 55 (2013) 176-184.

[41] T. Bandosz, Activated Carbon Surfaces in Environmental Remediation, Elsevier Science \& Tech2007. 
[42] R.J.J. Jansen, H. van Bekkum, XPS of nitrogen-containing functional groups on activated carbon, Carbon, 33 (1995) 1021-1027.

[43] Y.F. Jia, B. Xiao, K.M. Thomas, Adsorption of metal ions on nitrogen surface functional groups in activated carbons, Langmuir, 18 (2002) 470-478.

[44] S. Biniak, G. Szymanski, J. Siedlewski, A. Swiatkowski, The Characterization of activated carbons with oxygen and nitrogen surface groups, Carbon, 35 (1997) 1799-1810.

[45] C. Moreno-Castilla, F. Carrasco-Marín, A. Mueden, The creation of acid carbon surfaces by treatment with (NH4)2S2O8, Carbon, 35 (1997) 1619-1626.

[46] C. Moreno-Castilla, M.V. López-Ramón, F. Carrasco-Marín, Changes in surface chemistry of activated carbons by wet oxidation, Carbon, 38 (2000) 1995-2001.

[47] N. Grassie, R. McGuchan, Pyrolysis of polyacrylonitrile and related polymers-VI. Acrylonitrile copolymers containing carboxylic acid and amide structures, Eur. Polym. J., 8 (1972) 257-269.

[48] Y. Ji, T. Li, L. Zhu, X. Wang, Q. Lin, Preparation of activated carbons by microwave heating KOH activation, Appl. Surf. Sci., 254 (2007) 506-512.

[49] J.L. Figueiredo, M.F.R. Pereira, M.M.A. Freitas, J.J.M. Órfão, Modification of the surface chemistry of activated carbons, Carbon, 37 (1999) 1379-1389.

[50] T.C. Jorgensen, L.R. Weatherley, Ammonia removal from wastewater by ion exchange in the presence of organic contaminants, Water Res., 37 (2003) 1723-1728.

[51] B. Saha, M. Streat, Adsorption of trace heavy metals: Application of surface complexation theory to a macroporous polymer and a weakly acidic ion-exchange resin, Industrial and Engineering Chemistry Research, 44 (2005) 8671-8681.

[52] C. Ba, J. Economy, Preparation of PMDA/ODA polyimide membrane for use as substrate in a thermally stable composite reverse osmosis membrane, Journal of Membrane Science, 363 (2010) 140-148.

[53] A. Herriott, Organic Chemistry - Ch. 18 Carboxylic Acids, 2009.

[54] W. Zheng, Surface chemistry design and characterization of anion exchange and activated carbon fibers for critical contaminants removal, Materials Science \& Engineerng, University of Illinois at Urbana-Champaign2014. 